\title{
Setting access prices: A critique of the ACCC's approach in telecommunications
}

\author{
Henry Ergas ${ }^{1}$
}

\begin{abstract}
Any access-system prices in multi-service networks must meet two constraints. Firstly, 'the multi-service adding-up constraint'; that is, the sum of the regulated access charges across the range of services provided by the network must be no less than the amount which would the cover the costs of the network. Secondly, an inter-temporal or time-consistency constraint, under which the present value of the expected path of access charges over time must be no less than the initial cost. This paper argues that neither constraint is met by the access prices the ACCC has set in telecommunications.
\end{abstract}

Third-party access regimes, which impose on an incumbent an obligation to provide third parties with access to designated services and facilities at regulated terms and conditions, have become widespread in Australian infrastructure industries since the Hilmer Report (Independent Committee of Inquiry into Competition Policy in Australia 1993) and the subsequent implementation of National Competition Policy in 1995. A key component of these regimes is the setting of regulated access prices, and the desirability or otherwise of the regimes is likely to depend on just how efficiently these prices are set. In effect, even if there were a market failure (presumably associated with monopoly power) that third-party access was intended to cure, whether the resulting cure increases social welfare must depend on just how severe 'government failure' will be in the implementation of that cure.

The central proposition of this paper is that in telecommunications regulated access prices have been characterised by serious inefficiencies. There has, in other words, been substantial 'government failure' in the regulatory regime.

Evaluating the extent of the resulting 'government failure' is complex. While it is readily accepted that access prices should ensure recovery of the costs access providers efficiently incur (Productivity Commission 2001 and 2002), 'costs' are not, from the standpoint of the economist's subjectivist view, a simple construct

\footnotetext{
${ }^{1}$ Concept Economics, HenryErgas@concepteconomics.com.au. I am very grateful to Eric Ralph and Alexis Hardin for their help in the preparation of this article. I also acknowledge my debt to Telstra, as my appreciation and understanding of these issues has originated in my consultancies. Finally, I am grateful to the Editor, for several helpful comments on the initial draft. The views expressed here are, of course, strictly my own.
} 
that is readily capable of objective verification (Buchanan 1969/1998: 43). The problems of cost verification are all the more difficult in infrastructure industries, where the bulk of costs are sunk and involve capital assets for which there are no, or few, secondary markets. Moreover, in telecommunications, all of these problems are accentuated by the presence of pervasive economies of scale and scope, by the sheer technical complexity of telecommunications networks and by rapid technological change. Finally, any evaluation of regulatory decisions is hindered by the fact that those decisions are often themselves complex and opaque, and may involve data not all of which is in the public domain.

Those difficulties notwithstanding, this article presents a critical evaluation of telecommunications access pricing, as it has been determined by the Australian Competition and Consumer Commission (ACCC). The focus is not on how those prices compare to 'costs' but, rather, on how well they compare to some de minimis benchmarks that can be readily derived both from the economic theory of access pricing and from the 'thought experiment' on which the ACCC has relied in its approach to telecommunications costing.

Specifically, I examine the degree to which access pricing decisions have been consistent with an adding-up criterion, in which prices, aggregated across regulated services and over time, must recover total costs. I find that this criterion is not met, both with respect to the structure of prices at any point in time and with respect to the path of prices over time.

The structure of this paper is as follows. I begin by explaining some key features of the institutional context and the powers it vests in the ACCC. I then discuss the approach the ACCC has used to cost telecommunications services and derive from it two crucial consistency tests: the first relates to whether costs 'add up' as between the full set of regulated services, and the second to cost recovery over time. On that basis, I briefly consider some factors which may explain the observed outcomes and then conclude with some recommended changes to the regime.

\section{The legal framework}

Third-party access rights are provided for in Australia under both economy-wide instruments and through legislation specific to particular industries. The economy-wide regime is set out in Part IIIA of the Trade Practices Act, which was enacted in 1995 subsequent to the Independent Committee of Inquiry into Competition Policy in Australia (the 'Hilmer Report' of 1993). Importantly, a separate access regime for telecommunications is set out in Part XIC of the Trade Practices Act, which came into effect in July 1997 and differs in significant respects from Part IIIA. ${ }^{2}$

\footnotetext{
2 There are also specific access regimes for natural gas and for electricity. However, unlike the telecommunications regime, these broadly operate within the Part IIIA framework.
} 
While there are significant differences between these access regimes, there are some broad 'architectural' similarities. In Australian access regimes, the precise scope of mandated third-party access is typically determined not by statute but by an essentially administrative process which includes or excludes individual services from a requirement to provide access. What is determined by statute are the mechanisms involved in that process as well as the broad criteria that process must consider, so that it is through these (as well as through the attitude adopted by the administrative decision-makers) that the degree to which the regime is 'conservative' (that is, restrictive) in granting access is determined.

In Part IIIA and in Part XIC, services covered by the regime are said to be 'declared'. However, the criteria and relevant process for declaration differ and there are more stringent checks and balances against declaration in the former regime than in the latter. ${ }^{3}$

The main result of these differences is that far more services have been declared under Part XIC than under Part IIIA. Moreover, Part XIC declarations have involved a number of services that are close substitutes and some that are simply intended for resale. Both of these outcomes would not be possible under Part IIIA. Finally, very few services have had declaration revoked or subsequently limited under Part XIC.

Once a service is declared, the ACCC can, in the event of dispute between an access seeker and an access provider, use powers of mandatory arbitration to determine the terms and conditions of access to that service. Under both Part IIIA and Part XIC, an access provider also has the scope to submit an Undertaking setting out the terms and conditions on which it will provide a service. If the Undertaking is accepted, the ACCC must arbitrate an access dispute in a manner consistent with that Undertaking. The Undertaking, in other words, provides access providers and access seekers with a degree of certainty as to the terms and conditions of access.

In practice, the Undertaking mechanism under Part XIC has not been effective, in the sense that Undertakings are rarely accepted for key services. To date, only two Undertakings offered by Telstra have been accepted, one that merely copied the indicative prices issued by the ACCC immediately prior to the Undertaking being lodged, while another had very short duration (and was

\footnotetext{
3 Thus, in Part IIIA, the criteria for declaration involve a list of hurdles, each of which must be met, while Part XIC simply involves a number of loosely-specified criteria which can be traded off. Additionally, declaration decisions under Part IIIA are made on the recommendation of the National Competition Council, which plays no part in regulating declared services. Those decisions are then subject to review by a Minister and, if appealed, by the Australian Competition Tribunal ('ACT'). In contrast, under Part XIC, declaration decisions are made by the ACCC, which then regulates access to the service. In that sense, the regulator is in a position to expand the scope of its own control. Moreover, those decisions are not subject to review on the merits.
} 
accepted on the basis of that fact). ${ }^{4}$ All the other Undertakings offered by Telstra have been rejected, as have the Undertakings offered by SingTel Optus and by Vodafone. There is a right to appeal to the Australian Competition Tribunal for review on the merits of decisions in respect of Undertakings. All such appeals by Telstra, Optus and Vodafone have failed.

When an Undertaking is not in place, the ACCC must arbitrate disputes taking account of a list of considerations set out in the legislation. Here, too, Part XIC differs from the other access regimes. These differences go both to the substance of the factors the ACCC must take into account and to the relevant process.

With respect to the factors, Part IIIA was initially relatively non-prescriptive regarding the determination of the terms and conditions of access to services brought within the scope of the access regime - indeed, its broad structure was similar to that of Part XIC.

Thus, many of the provisions which the ACCC was initially required to take into account in setting access charges under Part IIIA were very general in character and hence capable of wide interpretation, much like the analogous provisions in Part XIC. Under s44X (the section of Part IIIA which defines the relevant criteria but to which other sections, discussed below, have now been added), the 'legitimate business interests' of the service provider must be considered, as well as the interests of those with a right to use the service. The section also requires some assessment of the competitive benefit of access, such that the ACCC must consider the 'public interest in having competition in markets'. Consideration must also to be given to 'the direct costs of access'. These considerations are substantially similar to the 'laundry list' of factors set out, for the determination of access disputes, in s152CR of Part XIC.

Additionally, the legislation did not assign weights to the criteria in the section; it simply obliged the ACCC to have regard to each and every factor. As a result, the ACCC could simply trade one factor off against another, thereby determining disputes much as it thought fit.

This situation has changed as significant modifications have been made to Part IIIA and, specifically, to s44X (changes which have not been replicated in Part XIC). The most important change is the insertion of 'pricing principles' which the ACCC must take into account. One of these principles requires that the regulated price be sufficient to at least cover the efficient costs of providing access, including a return commensurate with regulatory and commercial risk.

\footnotetext{
${ }^{4}$ Telstra's 2003 Public Switched Telephone Network Originating and Terminating Access (PSTN OTA) undertaking was accepted primarily because 'Telstra's proposed disaggregated PSTN O/T rates result in headline rates only marginally above Commission's model price terms' (see ACCC 2004a: 2). Telstra's 2003 LCS undertaking was accepted, inter alia, 'given ... the fact that the LCS undertakings will only apply for six months' (Ibid).
} 
In contrast, under Part XIC, there is no explicit requirement for access prices to cover costs.

Regarding the process by which access charges are set when an access Undertaking is not in place, the most significant difference is that Part XIC does not provide for a right of review on the merits of ACCC arbitration decisions, while Part IIIA and its associated regimes generally do. Effectively, if an Undertaking is not in place, there are few constraints on the manner in which the ACCC can set access charges under Part XIC.

The manner in which the pricing discretion vested in the ACCC has been implemented reflects an additional important feature that differentiates the telecommunications access regime from its counterparts, and particularly those in the energy industries.

In energy, regulators generally set an overall price or revenue cap for a fixed period of time, typically five years. That overall cap then sets a constraint within which the regulated entity determines the level of individual regulated prices; that is, the price structure.

In contrast, under the telecommunications regime the regulator determines prices for individual services from time to time, with redeterminations being triggered by access disputes. As a result, a particular access charge - say the access for the wholesale version of the line-rental services - may be determined several times in the course of a few years, if bilateral access disputes with respect to that service are brought to the ACCC for arbitration. Moreover, that price may be set without regard to how other prices for regulated access services have been determined, except to the extent to which the ACCC chooses to take account of those other prices in its final determination.

The process of setting access prices in telecommunications is therefore inherently more discretionary, messier and more vulnerable to changing and potentially inconsistent regulatory decision-making than is the case in the other Australian access regimes.

\section{The ACCC's measure of costs}

Ultimately, every form of access pricing involves some consideration of the costs of supply. Regulators face a choice in this respect between alternative cost bases.

Faced with that choice, the ACCC has relied not on historical costs (that is, the outlays actually incurred in acquiring and operating assets) but, rather, on current costs. While the term 'current cost accounting' covers several differing methodologies (see Ma and Mathews 1979: 478ff.), common to these methodologies is that cost estimates are based on current input prices and technologies (and expectations about future input prices and technologies) rather 
than on amounts actually outlaid in the past. They are in this sense 'forward' rather than 'backward' looking.

At a conceptual level, forward-looking approaches can be seen as involving a particular kind of 'fair bargain' between the regulated firm and the regulator. In this bargain:

1. The firm agrees to undertake an investment; in exchange for which

2. The regulator agrees to provide the firm with an income in each future period which reflects the current cost of its assets in that period, as well as an efficient level of operating expenses; where, if the participation constraint is to be met,

3. The expectation of that current cost income stream is equal, in present value terms, to the cost of the investment and of its associated flow of operating expenses.

Whether this version of the regulatory contract is likely to be economically efficient is a contentious issue, but there are good reasons for believing it is not. Rather, it can be argued that when eliciting efficient investment is important, a simpler, more readily verified form of regulatory contract, such as one based on historical costs, would seem preferable. ${ }^{5}$ That said, it is still sensible to take this regulatory contract at face value and look at how it has been implemented.

In doing so, it is useful to start from the thought experiment that underlies the particular forward-looking costing methodology on which the ACCC has mainly relied. That methodology involves estimating the Total Service Long Run Incremental Cost (TSLRIC) of service provision. ${ }^{6}$

In essence, TSLRIC (and its close cousin, Total Element Long Run Incremental Cost (TELRIC) $)^{7}$ has three core elements: the relevant increment that is costed is defined as the total volume of the service at issue (for instance, the total telephony traffic carried over the network); the decision at issue is taken to be whether the increment is supplied over the longer run - so that the capital stock is fully variable, and hence is included in the cost pool; and the concern is with the resources that would be needed to provide this service with current technology and management practices, as against those that may have been inherited from earlier periods.

\footnotetext{
${ }^{5}$ See Wright et al. 2006, who conclude that given stochastic costs, forward-looking access prices retard investment and are generally dominated by access prices determined by historical cost whenever investment is desired. A contrary view, though not one that is formally demonstrated, can be found in Baumol and Sidak 1995.

6 The only comprehensive guide that I know of to TSLRIC is Ergas 1998.

${ }^{7}$ The ACCC claims that its approach to forward-looking costing in telecommunications involves TSLRIC. Technically, this is not correct, as it is really a variant of TELRIC. However, I will follow the ACCC in referring to it as TSLRIC.
} 
While implementation of TSLRIC is highly complex, its economic essence is not. What this cost concept seeks to reproduce is the minimum stream of payments a regulator would need to commit to so as to induce an access provider to build and operate a new, fully efficient, wholesale-only network capable of providing the access service. It is 'as if"' a Telstra-specific bomb (similar to the neutron bomb of the 1980s, but limited in its impact to the Telstra network) had been detonated, and the regulator put out to tender the right to construct and operate a replacement network. Assuming the tender was effectively competitive, the required compensation to the new builder would reflect the ideal TSLRIC estimate.

In practice, that compensation is not provided as a lump sum but through a set of charges for a range of services. Moreover, as noted above, those charges are subject to periodic redetermination, usually on a service-by-service basis. As a result, if the payments over time are to indeed reflect the costs of the hypothetical, wholesale-only, new-build network, two interrelated sets of constraints must be met.

The first is a multi-service adding-up constraint. The sum of the regulated access charges across the range of services provided by the network must be no less than the amount which would the cover the costs of the network.

The second is an inter-temporal constraint, under which the expected path of access charges over time must be no less, in present value terms, than the initial cost. Clearly, were this condition not expected to be met, no investor would enter voluntarily into the 'regulatory bargain'. This is no different from the familiar concept of time-consistency in economic policy. ${ }^{8}$

In the remainder of this paper, I examine the ACCC's telecommunications access pricing decisions relative to these two constraints.

\section{The adding-up constraint}

Telecommunications networks are characterised by extensive economies of scope (that is, cost savings that result from providing many different services jointly). Those economies arise from the fact that many services are provided over a common set of assets, most notably the links that run from customers' premises to points of traffic aggregation (such as routers, multiplexers and switching systems) and shared traffic-management facilities (including switching and network-management systems). Reflecting those economies, the incremental costs of any particular service tend to be low relative to average costs (that is,

\footnotetext{
${ }^{8}$ Time-inconsistency arises when a policy that is optimal (from the point of view of the regulator) ex ante turns out not to be the optimal policy ex post. If the policymaker cannot commit to a policy, it may then find itself wanting to change its policy ex post (say, after a firm has made its investment decision), regardless of what it said ex ante. Such an approach to policy is said to be time-inconsistent (Kyland and Prescott 1977).
} 
the unit cost of all traffic considered jointly). ${ }^{9}$ As the ACCC itself has stressed, were access charges set only on the basis of incremental costs, total costs would never be recovered and long-run supply would be compromised. ${ }^{10}$

Forward-looking costing systems deal with this through cost-allocation rules that attribute to each service responsibility for recovering some share of joint and common costs. Those rules work on the basis of 'cost drivers', which (at the network level) involve the attribution of the costs of individual network elements to services on the basis of each service's share of each network element's use. A key feature of these rules is that the resulting allocations 'add up'. A failure to 'add up' obviously implies a shortfall between total costs and the revenues that would be generated were each service sold, by the hypothetical operator, at a price that reflected its allocated cost responsibility. Any regulatory outcome that thus failed to 'add up' would breach the participation constraint that underpins the TSLRIC thought experiment (that is, would not induce the construction of a new network capable of providing the set of services).

In practice, the ACCC's setting of telecommunications access prices has failed to respect the multi-service adding-up constraint. This is for two reasons. First, prices for individual services have been set below attributed costs without the resulting shortfall being added to the amount to be recovered from other services. Second, price structures have been set in such a way that arbitrage between services would impede full cost recovery from ever being achieved. I deal with each of these in turn in the discussion below. As that discussion requires some familiarity with the nomenclature of telecommunications, sets out a list of the various telecommunications services that are referred to in this paper, along with their standard abbreviations and a brief description of what each service involves.

\footnotetext{
9 Strictly speaking, average costs are not generally uniquely defined for a multi-product technology. Here, the term is used to refer to the unit cost estimate generated by the unique cost allocations of a particular TSLRIC model.

to The importance of recovering common costs is recognised by the ACCC in ACCC 1997: 39 and 41; and footnote 41 .
} 
Table 1: Key Telecommunications Terms and Acronyms

\begin{tabular}{|c|c|c|}
\hline Abbreviation & Name & Description \\
\hline ADSL & Asymmetric Digital Subscriber Line & $\begin{array}{l}\text { A broadband technology offering high } \\
\text { speed internet access. 'Asymmetric' means } \\
\text { data is transmitted 'downstream' to the } \\
\text { customer faster than it is sent 'upstream' } \\
\text { to the service provider. }\end{array}$ \\
\hline CAN & Customer Access Network & $\begin{array}{l}\text { Enables the connection of customer } \\
\text { equipment to switching equipment in a } \\
\text { telecommunications network. It consists } \\
\text { of a network of conduits and pipes with a } \\
\text { mixture of cables. }\end{array}$ \\
\hline LCO & Local Call Over-ride & $\begin{array}{l}\text { Access seekers can provide local carriage } \\
\text { service over Telstra's network either by } \\
\text { using the Local Carriage Service, or by } \\
\text { using the PSTN OTA service (see below). } \\
\text { The latter involves 'over-riding' the default } \\
\text { routing of the call by inserting a } \\
\text { long-distance code in front of the called } \\
\text { number and hence is referred to as 'Local } \\
\text { Call Over-ride'. }\end{array}$ \\
\hline LCS & Local Call Service & $\begin{array}{l}\text { A service for local call resale. It provides } \\
\text { for the carriage of telephone calls from } \\
\text { customer equipment at an end-user's } \\
\text { premises to separately located customer } \\
\text { equipment of an end-user in the same } \\
\text { standard charging zone. }\end{array}$ \\
\hline LSS & Line Sharing Service & $\begin{array}{l}\text { Enables a Telstra competitor to use the } \\
\text { high-frequency part of the phone line to } \\
\text { provide ADSL using its own equipment, } \\
\text { while Telstra still provides the normal voice } \\
\text { service. }\end{array}$ \\
\hline PSTN & Public Switched Telephone Network & $\begin{array}{l}\text { The global collection of interconnects } \\
\text { originally designed to support } \\
\text { circuit-switched voice communication. The } \\
\text { PSTN provides the traditional Plain Old } \\
\text { Telephone Service (POTS) to residences } \\
\text { and many other establishments. Parts of } \\
\text { the PSTN are also utilized for xDSL, VoIP } \\
\text { and other Internet-based network } \\
\text { technologies. }\end{array}$ \\
\hline PSTN OTA & $\begin{array}{l}\text { Public Switched Telephone Network } \\
\text { Originating and Terminating Access }\end{array}$ & $\begin{array}{l}\text { The PSTN originating and terminating } \\
\text { access services respectively allow access } \\
\text { seekers to buy the carriage of telephone } \\
\text { calls from a calling end-user to a point of } \\
\text { interconnection (POI) with the access } \\
\text { seeker's network, and the carriage of } \\
\text { telephone calls from a POI to a receiving } \\
\text { end-user. The two services allow } \\
\text { telecommunications companies to provide } \\
\text { services such as national long-distance } \\
\text { calls, international calls and calls between } \\
\text { fixed and mobile networks. }\end{array}$ \\
\hline TELRIC & Total Element Long Run Incremental Cost & $\begin{array}{l}\text { The incremental cost of supplying a specific } \\
\text { element of a network. It is defined as a } \\
\text { forward-looking long-run cost. }\end{array}$ \\
\hline TSLRIC & Total Service Long Run Incremental Cost & $\begin{array}{l}\text { The incremental cost of supplying an entire } \\
\text { service (such as telephony). It is defined } \\
\text { as a forward-looking long-run cost. }\end{array}$ \\
\hline ULLS & Unconditioned Local Loop Service & $\begin{array}{l}\text { Allows Telstra's competitors access to the } \\
\text { copper wire, without dial tone or carriage } \\
\text { service, between an end-user customer and } \\
\text { a telephone exchange. Competitors use the } \\
\text { ULLS with their own equipment in } \\
\text { exchanges to provide a range of services, } \\
\text { including traditional voice services and } \\
\text { high-speed internet access, to the end-user. }\end{array}$ \\
\hline
\end{tabular}




\begin{tabular}{l|l|l}
\hline Abbreviation & Name & Description \\
\hline WLR & Wholesale Line Rental & $\begin{array}{l}\text { Allows access seekers to resell the basic } \\
\text { line rental that allows an end-user to } \\
\text { connect to the traditional voice network, } \\
\text { make and receive voice calls and have a } \\
\text { telephone number. }\end{array}$ \\
\hline
\end{tabular}

\section{Local calls and adding up}

That the ACCC's price setting has resulted in regulated access prices being set below attributed costs is readily illustrated using the Local Call Service (LCS). That service is a 'resale' version of a retail service - local calling - that is directly price capped. Specifically, under the price-capping arrangements, the retail price for an un-timed local call is capped at 22 cents, excluding Goods and Services Tax (GST), with such an untimed service to be available nationally at an essentially uniform price. $^{11}$

The capped retail price for untimed local calls has generally been regarded both by Telstra and by the ACCC as being below the average cost of a local call, where that average cost is determined by attributing to local calls some responsibility for the joint and common costs of the network. Given that, the ACCC has had two options:

- It could set wholesale (that is, access) charges on the basis of attributed costs, so that the wholesale charge might exceed the capped retail price; or alternatively,

- It could set the wholesale charges on the basis of the capped retail price. To the extent to which this would result in those charges being below a relevant benchmark of costs, the issue of where the cost shortfall would be recovered by the hypothetical operator would need to be addressed so as to retain consistency with the underlying costing approach.

Some regulators, faced with this choice, have chosen the former approach on the basis that this places access seekers in a position that is competitively neutral with the access provider, as both incur a cost shortfall in supplying the price-capped services. The ACCC, however, has opted for the latter, which it has implemented by setting the wholesale price on the basis of subtracting from the capped retail price the cost of those activities that a wholesale-only provider would avoid (a price determination methodology generally referred to as 'retail minus'). As a result, to the extent to which there is a shortfall between the capped price and costs, that shortfall will remain and need to be recovered elsewhere.

\footnotetext{
11 Telstra Carrier Charges - Price Control Arrangements, Notification and Disallowance, Determination No. 1 of 2005, later amended by Telstra Carrier Charges - Price Control Arrangements, Notification and Disallowance, Determination No. 1 of 2005 (Amendment No 1 of 2006), clause 16 'Untimed local calls'. The effect of the requirements set out in the price determination in ensuring that call charges for an untimed local call are the same in all areas is discussed in ACCC (2005a, p. $111 \mathrm{ff}$.).
} 
The extent of the shortfall can be estimated by reviewing the ACCC's setting of LCS prices for 1999/00 and 2000/01, when it still disclosed detailed information on its cost estimates and methodology. The relevant estimates for those years are set out in Table 2, noting that the data required to make similar calculations for more recent years has not been disclosed by the ACCC.

Table 2: ACCC local call estimates and under-recovery of costs

\begin{tabular}{l|ll}
\hline & $\mathbf{1 9 9 9 / 0 0}$ & $\mathbf{2 0 0 0 / 0 1}$ (GST exclusive) \\
\hline Total costs allocated to local calls & 21.54 cents & 21.21 cents \\
Wholesale local-call price & 19.26 cents & 17.51 cents \\
Under-recovery per call & 2.28 cents & 3.7 cents \\
Number of local calls & 11,566 million & 11,987 million \\
\hline Under-recovery of costs (based on ACCC cost estimates) & $\$ 264$ million & $\$ 443$ million \\
\hline
\end{tabular}

Three points help explain the Table.

First, the ACCC, when it calculates the cost of PSTN services, allocates costs to all types of PSTN traffic, including local calls. ${ }^{12}$ For the years here at issue, the Commission allocated PSTN costs of 21.54 cents to each local call in 1999/00 and 21.21 cents to each local call in 2000/01 (see Table 2, first row).

Second, despite that cost allocation, the ACCC, in setting the price for LCS, used a retail-minus approach which involved starting with the retail price of local calls and then deducting the 'avoidable' local-call retail costs. For 1999/00 through to 2002 the ACCC used an estimate of 2.74 cents per call for retail costs and adjusted this to 2.49 cents when the GST was introduced on 1 July 2000. As a result, in 1999/00 the LCS price was 19.26 cents per call and in 2000/01 was 17.51 cents per call (see Table 2, second row).

Third, there was consequently an under-recovery of costs for each local call, that under-recovery being of 2.28 cents per local call in 1999/00 and of 3.70 cents per local call in 2000/01 (see Table 2, third row). The aggregate under-recovery was of $\$ 264$ million in $1999 / 00$ and of $\$ 443$ million in 2000/01. Additionally, the quantum of that under-recovery would have continued to increase up to 2002/03, as local-call minutes increased more rapidly than all call minutes until then.

That shortfall is essentially a common cost that the hypothetical builder of the new, wholesale-only network would have had to recover from other services. Consistency with the thought experiment therefore suggests that the shortfall should have been allocated to other access services, notably PSTN Originating and Terminating Access (OTA), and within that, largely to terminating switched

\footnotetext{
12 The sum of those allocated costs equals total costs, so that total cost recovery in the relevant thought experiment requires that each service be priced in such a way as to recover the share of costs allocated to it.
} 
access. ${ }^{13}$ Had that been done, total revenues from the hypothetical network would indeed have equalled total costs, both being evaluated using total call minutes. But the ACCC failed to make any such allocation - rather, it simply ignored the inconsistency in its price-setting. ${ }^{14}$

As a result, a cumulative shortfall that (capitalised to the present) probably amounts to close to $\$ 1$ billion, was simply placed upon Telstra, which was left with access charges plainly below the relevant costs as determined by the ACCC's costing methodology.

\section{Regulated price structures and the adding-up constraint}

Further failures to respect 'adding-up' constraints have arisen from substitution between declared services caused by inconsistencies in their relative prices.

The approach the ACCC has adopted to declaration has resulted in access charges needing to be determined for a wide range of services that are close, and in some cases very close, substitutes. Errors in setting relative prices for these services will have two consequences:

- They will distort production choices, as access seekers replace inputs that are 'over-priced' with those that are 'under-priced'. This is a first-order welfare loss (meaning, in this case, a distortion that potentially affects all of output, rather than merely having an effect at the margin); and

- When the 'under-priced' services are priced below costs (or make a contribution to common costs that is insufficient to allow all of those costs to be covered), the shift in access-seeker demand to these services will prevent full cost recovery (or worsen what would in any event have been losses).

Thus, access seekers can provide local carriage service over Telstra's network either by using the Local Carriage Service, or by using the PSTN OTA service. The latter involves 'over-riding' the default routing of the call by inserting a long-distance code in front of the called number and hence is referred to as 'Local Call Over-ride' (LCO).

\footnotetext{
13 OTA involves the origination and termination of switched calls over Telstra's PSTN (for example, from a calling customer preselected to Optus to a called customer who is preselected to Telstra, where both are connected to Telstra's Customer Access Network). In general, it is efficient to place higher mark-ups on terminating than on originating access, as it is more difficult for terminating access to be bypassed.

14 It is important to note that had the ACCC allocated the shortfall to other wholesale services, this would not mean that the shortfall would have been largely or entirely borne by access seekers. Rather, because the shortfall would have been allocated over all minutes of use, each user of the network, including Telstra, would have faced the same unit charge per end-minute-of-use. In contrast, under the ACCC's approach (of simply ignoring the shortfall), the deficit would only fall on Telstra. This is the natural consequence of the definition of the relevant increment. In the ACCC's approach, that increment is the total traffic carried over the PSTN. As a result, common costs are unitised over that total. Analytically, the shortfall is merely a common cost to the PSTN as a whole and hence would be spread over all the traffic making use of that network.
} 
From a technical perspective, LCO is a highly inefficient way of providing local carriage service as it requires between 1.5 and 2 times the resources actually needed to complete a local call. ${ }^{15}$ The additional amount is a pure waste of society's resources.

That waste notwithstanding, LCO accounts for a non-negligible share of total local calling minutes. This is because the ACCC prices LCS on an untimed basis, while pricing PSTN OTA (and hence LCO) on a timed basis (that is, access seekers are charged per minute of use). As a result, it is highly profitable for access seekers to use LCO, rather than LCS, for short-held calls. As local calls generated by businesses tend to be of below-average duration, this can be done by modifying the software businesses have on their PABXs (the private exchanges that manage their traffic) to insert an over-ride code into local calls.

LCO has two effects on the economics of the local carriage service. The first is that it results in the technical inefficiency discussed above. The second is that it aggravates the shortfall Telstra incurs in the supply of local calls.

That shortfall, discussed above, is aggravated because removing short-held local calls from the stock of local calls in and of itself saves very few costs. In effect, the costs of the inter-exchange network (the part of the network that goes between, and includes, local exchanges) tend to be almost completely insensitive to even substantial variations in traffic volumes. ${ }^{16}$ Moreover, in reality, LCO does not remove those calls but merely re-routes them through the inter-exchange network, potentially increasing the actual costs that Telstra bears (though Telstra's loss is partially offset by the LCO payment). On balance, revenues are reduced while no costs are avoided, reducing the extent of cost recovery even further.

Even more serious distortions have arisen as between the ULLS, WLR and LSS services, which are all access line services. Simplifying somewhat, these services are broadly alternative ways of providing the same set of end-user services, including telephony and ADSL.

The ACCC has set prices for these services in a manner that creates enormous scope for inefficient substitution. Underpinning these distortions is the fact that (1) retail prices for line-rental services are capped and (2) Telstra is required to

\footnotetext{
15 An LCO call must use a local switch at least twice (although a quarter or so of local calls would otherwise only use a local switch once), and additionally requires transmission resources to and from the access seeker's Point of Interconnection. The Point of Interconnection is the point at which the call exits the Telstra network and is handed over to the access seeker's network, where it is 'turned around' and handed straight back to the Telstra network for termination.

${ }^{16}$ For example, using the Hatfield model for seven U.S. States, the percentage of the dominant local exchange carrier's total costs that is traffic-sensitive can be calculated as ranging from 15.0 per cent (for Georgia) to 21.1 per cent (for New York). However, increasing traffic by 30 per cent above the default level specified in the model increases total costs in each of the States by less than 1 per cent. The cost savings associated with a similar reduction in traffic levels would be no greater.
} 
offer specified line-rental services at the same price in all parts of Australia (see Australian Competition Tribunal in Telstra Corporation Ltd (No 3) [2007] ACompT 3 (17 May 2007) at paras. 218-224). These regulatory constraints, applied at the retail level, then create issues for the setting of access charges.

Whether charges for line-rental service cover costs is controversial. It is likely that non-traffic-sensitive costs account for 80 per cent or more of total PSTN costs. Were those costs to be covered by line-rental charges, those charges would need to be substantially higher than they currently are, at least going by Telstra's estimates of network costs. However, what is clear is that the geographically averaged line-rental charge that is applied in non-metropolitan areas is significantly below the costs of providing line-rental service in those areas, with the gap being especially large in areas of sparse population settlement.

As with LCS, the ACCC has therefore faced a choice in terms of how it set access charges for WLR:

- It could set WLR charges on the basis of cost, which would have resulted in those charges exceeding retail line-rental charges in rural and remote areas; or alternatively,

- It could use a 'retail-minus' methodology, which would mean that charges would be well below costs, most clearly so in rural and remote areas.

The ACCC has chosen the latter approach.

At the same time, the ACCC has set charges for LSS on the basis of assuming that WLR charges, at least on average, entirely cover network costs, so that all that LSS charges need to cover are some incremental costs. ${ }^{17}$ Since these costs are assumed to be the same in all areas, the resulting LSS charge is geographically uniform.

Finally, the ULLS charge has been set so as to recover network costs in each area. Specifically, ULLS charges have been set by 'Bands', with Band 1 covering the CBDs, Band 2 being the main metropolitan areas (excluding the CBDs), Band 3 being outer metropolitan areas and non-metropolitan population centres (such as regional centres), and Band 4 covering rural and remote areas.

As a result:

- WLR and LSS charges are set on a geographically averaged basis, with the sum of these charges being well below costs in non-metropolitan areas;

- ULLS charges are set on a geographically de-averaged basis, and hence tend to be well above charges for WLR and LSS in non-metropolitan areas.

17 Originally, those incremental costs were the 'LSS-specific' costs - that is, the fixed set-up costs of providing and managing LSS. However, the ACCC subsequently changed its view on this and shifted to only allowing the LSS to recover a contribution to the averaged costs of managing all wholesale ADSL services - averaged costs that (given the number of ADSL services now in use) are very small. 
This 'mix and match' pricing methodology invites 'cherry picking', in which demand swings to the inputs that are relatively under-priced.

The 'cherry-picking' opportunities arise from the juxtaposition of geographically de-averaged charges for some declared services with geographically averaged charges for others that are substitutes for those that are geographically de-averaged. This juxtaposition makes it possible to use the declared services for which charges are geographically de-averaged in those areas where costs are low, while using the declared services for which charges are geographically averaged in those areas where costs are high.

Thus, for ULLS, which allows an access seeker to provide both voice and data services, the geographically de-averaged prices mean that (at the time of writing) access seekers can use Telstra's CAN at an access price of $\$ 6$ per month in CBD areas and \$14 per month in other metropolitan areas (2007/08 prices). The ACCC has not made any determination for ULLS prices in rural areas, and has not disclosed any recent estimate of ULLS costs in those areas. However, it has previously suggested that the price of ULLS in rural areas would be $\$ 100$ per month (see, for example, ACCC 2003: 84, Table 10.4) and research undertaken by the Productivity Commission suggests that costs in those areas are substantially higher. ${ }^{18}$

Whether the ULLS price in rural areas should be $\$ 100$ or $\$ 200$ per month is, however, in many respects irrelevant. In effect, the ACCC has set the charges for Telstra's CAN in rural areas on a geographically averaged basis. Thus, at the time of writing, access seekers can provide voice services in rural areas using the wholesale line-rental service for $\$ 23.12$ per month for residential customers and $\$ 25.84$ for business customers. ${ }^{19}$ At the same time, they can provide data service to those same customers using the (also geographically averaged) LSS service. The ACCC's most recent decision on LSS sets a geographically averaged price of just $\$ 2.50$ per month. ${ }^{20}$ The effective input price access seekers face for the CAN in non-metropolitan areas is therefore capped at some $\$ 26$ per month for residential customers and \$29 per month for business customers. These charges are obviously far below TSLRIC-based costs in those areas, even on the ACCC's estimates.

As a result, the ACCC's wholesale pricing allows the access provider to recover from access seekers no more than the cost of the CAN in low-cost areas and well below the cost of the CAN from access seekers in rural areas. No other access

\footnotetext{
18 See Productivity Commission 2000. This research indicates that line costs in low-density areas of Australia are six to 14 times higher than in the rest of Australia. Given the line density in rural areas of Australia and based on the ACCC's own cost estimates in other areas of Australia this suggests that monthly CAN costs in rural areas are in the order of $\$ 140$ to $\$ 209$ per line.

${ }_{19}$ See ACCC 2006.

20 See ACCC 2007 c.
} 
prices (not even those for services such as terminating access that face highly inelastic demand, so that they could be marked up to recover the resulting shortfall) have been increased to compensate. Total recovery must therefore fall short of total costs, as the multi-service adding-up constraint is breached.

\section{Time inconsistency}

Turning now to the issue of pricing over time, time inconsistency arises when a regulator will have incentives ex post to reverse commitments it may have wanted to make ex ante.

For example, given that many of Telstra's costs result from past investment that are now sunk, ex post the regulator may want to discount some of those costs, thereby reducing user charges. As Telstra's obligations to provide service prevent it from 'walking', the temptation for a regulator to gain public standing and political legitimacy by being seen to be tough, and by forcing down prices, can be very strong. However, those gains come at a steep long-run cost: as the regulated firm comes to expect such time-inconsistent conduct by the regulator, it either refuses to put new assets at risk or demands a higher risk premium for doing so. As a result, prices must ultimately rise, the quality and range of service must suffer, or both.

Most regulators therefore try to avoid acting in ways that are time inconsistent. Indeed, the ACCC itself, in its approach to regulating electricity transmission, has stressed the risks of time inconsistency and sought to make credible commitments to avoid it. ${ }^{21}$ This has not, however, been its approach in telecommunications, as can be seen from a consideration of the manner in which the ACCC has determined depreciation and the PSTN capital charge.

The capital costs determined in a TSLRIC model are essentially a lump of costs, and those costs need to be spread over time. One approach to doing so is to 'levelise' the capital charge; that is, set it such that its value is equal in each year of the asset's life. ${ }^{22}$ Adopting this approach, the annual capital charge would be calculated as:

$$
C_{l}=\frac{r}{1-(1+r)^{-n}} \cdot \sum_{t=1}^{n} \frac{\left(\bar{w}_{t} \times r+d_{t}\right)}{(1+r)^{t}}
$$

where:

$\mathrm{C}_{\mathrm{l}}$ is the levelised capital charge

$r$ is the WACC

$\mathrm{n}$ is the useful life of the asset

$\mathrm{w}$ is the written-down value of the asset

21 ACCC 2004b: 38ff.

22 See Ergas 1998 on the issues this involves. 
$\mathrm{d}$ is economic depreciation.

The issue of choosing between these approaches to determining the stream of costs first arose in the context of Telstra's PSTN Undertaking for 1997/98. In assessing that Undertaking, the ACCC commissioned NERA to estimate the TSLRIC of PSTN access.

NERA's view, which was clearly expressed in its report to the ACCC (NERA 1999), was that the depreciation profile used in the calculation of TSLRIC must reflect economic depreciation. ${ }^{23}$ If the depreciation profile that is actually used fails to mirror the economic depreciation profile, this will lead to a failure to recover the cost of investment over time.

NERA expressly rejected the use of an annuity approach to depreciation, stating that it is even less appropriate than straight-line depreciation because a constant annualised capital cost (depreciation plus cost of capital) means that depreciation increases each year; that is, it is actually back-loaded. While it is possible to tilt the annuity to allow for price and output declines, NERA argued that it requires a large tilt to achieve a declining depreciation profile over time.

Despite NERA's findings, the ACCC requested NERA to calculate results based on an annuity function. For call conveyance costs, NERA found that using an annuity function had a significant effect on the results: charges for the Undertaking period were 20 per cent lower than the results obtained using proxy economic depreciation profiles (NERA 1999: 63).

In its Final Report on the Assessment of Telstra's Undertaking (ACCC 1999: $60)$, the ACCC failed to rely on any of the NERA results that used economic depreciation profiles, instead relying solely on the annuity-based results, which were undertaken only as a sensitivity analysis by NERA and only at the suggestion of the ACCC (see NERA 1999: 63, footnotes 48 and 49).

The ACCC has, since that first Undertaking assessment, continued to rely on the tilted annuity for estimating the TSLRIC of both PSTN OTA and ULLS. In the case of ULLS, the effect of the tilted annuity formula is to steeply back-load the time profile of cost recovery. This is inconsistent with the profile of economic depreciation, as it fails to take into account other factors that impact on the value of the asset over time, such as wear and tear. ${ }^{24}$

However, even putting the contrast with economic depreciation aside, the central problem is that the ACCC has never brought the deferred costs to account.

\footnotetext{
23 The NERA report defines economic depreciation for any period as the change in the value of the asset during the period. The economic value of an asset at a particular point in time is the present value of expected future revenues derived from the output of the asset less the present value of the operating costs associated with running the asset.

24 This too was noted by NERA, which emphasised that even where asset prices are not falling over time, declining output and rising operating costs may still require a declining (that is, front-loaded) depreciation schedule — see NERA 1999: 11. See also the discussion of this point in Ergas 1998.
} 
Rather, at each assessment it has brought the counter back to zero, thus setting prices in a sequence of regulatory redeterminations 'as if' the deferred costs could be simply written off.

The consequences of this approach can be seen from Figure 1, which compares actual ULLS charges (displayed as a charge per ULLS line in nominal dollars on the Y-axis), as determined by the ACCC, with the charges that would have prevailed had the ACCC respected the time profile of cost recovery as implied by its initial cost modelling.

Figure 1: ACCC Decisions on Monthly Band 2 ULLS Charges, 2002 to 2007

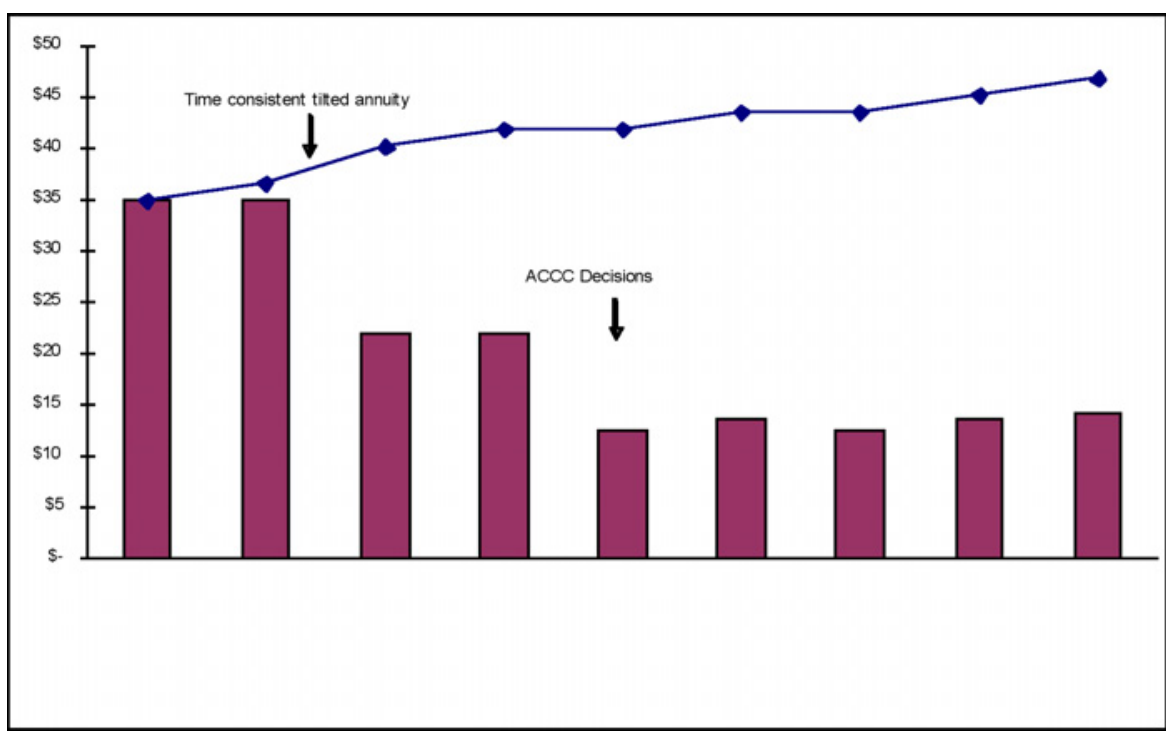

Sources: Calculated from ACCC (2002b), ACCC (2003), ACCC (2005b), ACCC (2007a).

Specifically, the line in Figure 1 provides an indication of what ULLS prices would have been had a time-consistent tilted annuity been applied to the Commission's initial pricing decision on ULLS. The points traced out by that line are the sequence of charges required for the 'fair bargain' to be paid out. The line slopes up as the ACCC's decision had deferred costs to future years, through the steep back-loading of the depreciation charge.

However, what the ACCC has done is not to set prices on the basis of that 'fair bargain'. Rather, in part by constantly restarting the clock, the ACCC has reduced its estimate of the TSLRIC of ULLS in Band 2 areas from $\$ 35 /$ service/month to just $\$ 13.90 /$ service/month (see bars in Figure 1).

What is striking is not only the extent of the overall reduction (and hence of the departure from the pattern of prices implied by the tilted annuity) but also its pattern. In effect, as estimated by the ACCC, costs largely decrease, often sharply, but there are only exceptionally moderate rises. However, if depreciation 
in a forward-looking cost model is set on an actuarially fair basis, the changes in costs at re-estimation should follow a normal distribution (so long as cost shocks are independent), as it should be as likely that the initial estimate of depreciation (which reflects the anticipated change in asset values) will be an underestimate as it is that it will be an overestimate. This contrasts with the pattern of the successive ACCC estimates. ${ }^{25}$

The author's explanation of this outcome is that what the ACCC has done is to ignore the price path implied by its back-loaded depreciation profile, while successively reducing the estimate of the levelised cost. These reductions are equivalent to writing off the amount that (through the back-loading of the annuity) had implicitly been deferred to each period from previous periods.

The extent of the resulting cost-recovery shortfall is large in absolute terms. It can be quantified in terms of the loss that would be borne by the hypothetical, wholesale-only, access provider, operating a continuously fully optimised network. That amount, taken as a loss compounded from 2002 to the present at an interest rate of 10 per cent, approaches $\$ 22$ billion.

\section{Outcomes}

Overall, the ACCC's setting of telecommunications access prices does not seem to meet basic consistency tests that are inherent in its own cost standard. The resulting tensions have been aggravated by the fact that repeated application of the ACCC's approach has resulted in price declines that are strikingly large, both in absolute terms and relative to experience overseas.

Thus, in real (inflation-adjusted) terms, regulated access charges declined:

- For LSS, an annual rate of 28.2 per cent over the period from September 2002 to September 2007;

- For ULLS, an annual rate of 12.7 per cent over the period from April 2002 to September 2007; and

- For PSTN OTA, an annual rate of 7.1 per cent over the period from September 1997 to September 2007;

It is difficult to believe that costs could have declined at rates close to the rates mandated by the ACCC. Even on the ACCC's own estimate, total factor productivity in Telstra's fixed network has been increasing at an annual average rate of 5.4 per cent, and (in trend terms) of less than two per cent. ${ }^{26}$ Moreover,

25 Of course, it is not impossible that a 'technology surprise' would have occurred that reduced costs by some 60 per cent. However, there is no evidence of such a surprise nor has the ACCC ever claimed such a surprise has occurred. A reduction in ULLS-specific costs (that is, the incremental costs associated with making the ULLS service available to access seekers) also occurred over the period, but it accounts for a small share of the observed reduction in prices.

${ }^{26}$ The ACCC's estimate of 5.4 per cent is heavily influenced by what appears to be a data error in respect of a single year (2000/01). When a trend is fitted, excluding that year, the resulting rate is 1.6 per cent, 
even with that total factor productivity growth, input prices (for important items such as copper and trenching) have been rising in nominal terms, as the China boom has increased world demand for those inputs. Simulations with Telstra's forward-looking cost model suggest that each one per cent increase in the price of copper-based network elements increases the average cost of ULLS by 0.24 per cent: between July 2002 and July 2006 copper prices increased by 386 per cent. At the same time, prices for the other key inputs (notably labour and fuel) have also increased, in both nominal and real terms. ${ }^{27}$ As a result, the expected trend would be for nominal access charges based on replacement costs to be rising - not decreasing at dramatic rates (since these input price rises have exceeded reasonable estimates of total factor productivity growth).

Underscoring this point is the fact that the ACCC's initial access charges from which these very large declines have occurred - were derived from estimates of costs for a fully optimised network: that is, for a network that had already achieved all the efficiencies that could be secured. As a result, productivity growth for this 'ideal' network would likely be significantly slower than that achievable in the actual network, as some of the productivity growth in the latter will be 'catching up' to best practice (that is, to the technological frontier). This makes it even more unlikely that the declines mandated by the ACCC reflect trends in costs.

Why has this happened? There is not the space here to explore this question systematically, but four explanations are worth noting.

First, particularly in the early years, there was a widespread belief that Telstra, like other former monopolies, was far from efficient, and that social welfare would be improved, or at least not compromised, by an aggressive attitude to the setting of access prices. Moreover, the ACCC may well have believed, and continue to believe, that any costs associated with setting access prices on the low side were outweighed by gains that could come from kick-starting competition, though there is, in the author's opinion, little evidence that would back that assessment.

Second, the ACCC, like other regulatory bodies, seeks public legitimacy, which is presumably more readily secured when prices to consumers are being cut, and drastically so, than when they are being increased. The fact that telecommunications has become ever more important and visible to consumers (be they residential consumers or businesses) has likely accentuated this effect. Moreover, especially prior to full privatisation, the cost of unjustified access-price

which is close to the author's own best estimate, which is around 2 per cent. The ACCC estimates are in ACCC 2005a.

27 Prices for electronics have been falling, but electronics accounts for a small share of the cost of a ULLS network. The main cost items in such a network are copper, trenching, maintenance labour and fuel. 
reductions fell on taxpayers, a large and dispersed group, while the benefits flowed to groups that were far more concentrated, namely access seekers (at least in the short term), the ACCC (through enhanced legitimacy) and the government of the day (which could point to the success of its policies, and use that success to promote its goal of privatisation).

Third, and related, telecommunications is an exclusive Commonwealth responsibility under section $5 \mathrm{l}(\mathrm{v})$ of the Constitution. ${ }^{28}$ As a result, the process which has occurred in the energy industries, where individual States have sought to protect from what they have seen as undue regulatory discretionary the financial integrity of their energy industries, has not operated to hem in the powers vested in the ACCC.

Lastly, the appeal mechanisms in the telecommunications access regime are deeply unsatisfactory (see Ergas 2008), and have been much less effective than in the energy industries in providing checks and balances in respect of regulatory discretion.

\section{What can be done about it?}

Individual instances of regulated price setting will always be complex and contentious. This will be all the more the case in telecommunications, given its technical complexity and the rate at which telecommunications technology advances. Further complications arise from the wide range of services the ACCC has sought to regulate, a range that includes many services that are substitutes, as well as several for which retail prices are also directly regulated. Given those circumstances, there will always be arguments about any particular instance of regulatory price setting.

Nonetheless, there are a few steps (discussed in greater detail in Ergas 2008) that could greatly improve the process of regulatory price setting.

First, too many telecommunications services are regulated. Greatly reducing that number, to one or, at most, a very few bottleneck services (for example, the local loop), would eliminate some of the complexities that have bedevilled the process.

Second, clearer pricing principles are needed to guide the ACCC, with a requirement for reasonable cost recovery being central among them. Ideally, those principles would (as occurs in energy) be translated into rules for the regulator by a rule-making entity that was entirely separate from the regulator itself.

\footnotetext{
${ }^{28}$ Section 51(v) of the Australian Constitution provides that 'The Parliament shall, subject to this Constitution, have power to make laws for the peace, order, and good government of the Commonwealth with respect to:- (v.) Postal, telegraphic, telephonic, and other like services.'
} 
Third, to the extent to which several services continue to be regulated, the regime should shift from controlling individual prices to setting an aggregate price or revenue cap. This would make it easier to respect adding-up constraints and to avoid creating inefficient arbitrage opportunities. While retail price regulation will always create complex challenges for the regulation of wholesale prices, the ACCC could have completely avoided the adding-up problems it fell into had it moved to a single wholesale price cap (as this author advocated long ago), since such a cap would have allowed revenue losses on retail price-constrained services to be made up for through higher wholesale prices on inelastic services.

Fourth, such a cap should be set for a lengthy period, so as to reduce the risk of time inconsistency. Particularly as significant new investment is sought in a high-speed broadband network, anything other than a long regulatory period — probably as long as the life of the asset — is merely likely to introduce undesirable regulatory risk.

Last but not least, greater transparency would help. As the ACCC has regulated more and more, it has, at least in this author's view, tended to disclose less and less. A requirement for full transparency of the ACCC's calculations (including the detailed workings), where that can be provided without compromising commercial confidentiality, would help make the process more accountable.

\section{References}

Australian Competition and Consumer Commission (ACCC) 2007a (November), 'Unconditioned Local Loop Service, Final Pricing Principles'. 2007b (December), 'Primus/Telstra ULLS, Final Determination'. 2007c (August), 'Request/Telstra LSS, Final Determination'. 2006 (November), 'Pricing Principles and Indicative Prices: Local Carriage Service, Wholesale Line Rental and PSTN Originating and Terminating Access Services, Final Determination and Explanatory Statement'. 2005a (February), 'Review of Telstra's Price Control Arrangements: Final report'.

2005b (December), 'Assessment of Telstra's ULLS and LSS Monthly Charge Undertakings, Final Decision'.

2004a (December), 'Assessment of Telstra's Undertakings for PSTN, ULLS and LCS: Final Decision'.

2004b (December), 'Decision: Statement of Principles for the Regulation of Electricity Transmission Revenues - background paper'. 
2003 (October), 'Final Determination for Model Price terms and Conditions of the PSTN, ULLS and LCS Services'.

2002a (April), 'Local Carriage Service Pricing Principles and Indicative Prices, Final Report (Revised)'.

2002b (March), 'Pricing of Unconditioned Local Loop Service, Final Report'.

2000 (July), 'A Report on the Assessment of Telstra's Undertaking for Domestic PSTN Originating and Terminating Access Services'.

(1999), Assessment of Telstra's Undertaking for Domestic PSTN Originating and Terminating Access, Final Decision, June.

1997, 'Access Pricing Principles: Telecommunications — a Guide.

Baumol, W. and Sidak, G. 1995, Transmission Pricing and Stranded Costs in the Electric Power Industry, AEI Press, Washington D.C.

Buchanan, James M. 1969/1998, Cost and Choice, Liberty Press, Indianapolis.

Ergas, H. 1998, 'TSLRIC, TELRIC and other forms of forward-looking cost models in telecommunications: a curmudgeon's guide' at:

www.greenwhiskers.com.au/papers_reports/papers-ergas-tslric-final-nov98.pdf

Ergas, H. 2008, Wrong Number: Australia's Telecommunications Mess and How to Fix It, Allen \& Unwin, Sydney.

Fabrycky, W. J., Thuesen, G. J. and Verma, D. 1998, Economic Decision Analysis, 3rd ed., Prentice Hall, Upper Saddle River, New Jersey.

Freidenfelds, J. 1981, Capacity Expansion: Analysis of Simple Models with Applications, North Holland, New York.

Independent Committee of Inquiry into Competition Policy in Australia 1993, National Competition Policy ('the Hilmer Report'), Australian Government Publishing Service, Canberra.

Kyland, F. and Prescott, E. 1977, 'Rules Rather than Discretion: The Inconsistency of Optimal Plans', Journal of Political Economy 85: 473-92.

Ma, R. and Mathews, R. 1979, The Accounting Framework, Longman Cheshire, Melbourne.

Manne, A. S. 1967, Investments for Capacity Expansion, MIT Press, Cambridge, Mass.

NERA 1999 (January), 'Estimating the Long Run Incremental Cost of PSTN Access, Final Report for ACCC'.

Productivity Commission 2002, 'Review of the National Access Regime, Inquiry Report No. 17'. 
2001, 'Telecommunications Competition Regulation, Report No. 16'. 2000, 'Population Distribution and Telecommunication Costs', Staff Research Paper.

Revsine, J. 1979, 'Technological Change and Replacement Costs', The Accounting Review 54: 306-22.

Whittington, G. 1983, Inflation Accounting: An Introduction to the Debate, Cambridge University Press, Cambridge.

Wright, J., Guthrie, G. and Small, J. 2006, 'Pricing Access: Forward versus Backward Looking Cost Rules', European Economic Review 50: 1767-89. 